\title{
AVALIAÇÃO ERGONÔMICA DO AMBIENTE CONTRUIDO: ESTUDO DO SETOR DE HEMODINÂMICA DE UM HOSPITAL UNIVERSITÁRIO À LUZ DA METODOLOGIA ERGONÔMICA DO AMBIENTE CONTRUÍDO (MEAC)
}

\author{
ERGONOMIC EVALUATION OF THE BUILT ENVIRONMENT: A \\ STUDY OF THE HEMODYNAMICS SECTOR OF A UNIVERSITY \\ HOSPITAL IN THE LIGHT OF THE ERGONOMIC METHODOLOGY OF \\ THE BUILT ENVIRONMENT (MEAC)
}

\author{
Alaíde Farias, Enfermeira (1); \\ Marcelo Gomes, Pedagogo (2); \\ Marilande Silva, Enfermeira (3); \\ Waldelourdes Melo, Enfermeira (4); \\ Vilma Villarouco, Dr ${ }^{\mathrm{a}}$ em Engenharia de Produção (5). \\ 1. Universidade Federal de Pernambuco. \\ Email: alaideff@hotmail.com \\ 2. Universidade Federal de Pernambuco. \\ Email: marceloh2@yahoo.com.br \\ 3. Universidade Federal de Pernambuco. \\ Email: marilande_andrade@hotmail.com \\ 4. Universidade Federal de Pernambuco. \\ Email: walmelosoutomaior@gmail.com \\ 5.Universidade Federal de Pernambuco. \\ Email:villarouco@hotmail.com
}

Palavras-chave: Ergonomia, Hemodinâmica, Ergonomia do ambiente construído. 


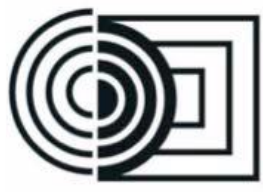

$16^{\circ}$ Ergodesign - Congresso Internacional de Ergonomia e Usabilidade de Interfaces Humano Tecnológica: Produto, Informações Ambientes Construídos e Transporte

$16^{\circ}$ USIHC - Congresso Internacional de Ergonomia e Usabilidade de Interfaces Humano Computador

CINAHPA | 2017 - Congresso Internacional de Ambientes Hipermídia para Aprendizagem.

Estudo realizado na Hemodinâmica de um Hospital Universitário, utilizando a Metodologia Ergonômica para o Ambiente Construído (MEAC), proposta por Villarouco (2008), visando um diagnóstico de adequação do espaço aos seus usuários. Os resultados mostraram as reais necessidades de ajustes para 0 ambiente atender às demandas, a fim de alcançar os objetivos da Ergonomia.

Keywords: Ergonomics, Hemodynamic Ergonomics, of the built environment.

A study carried out in the Hemodynamics of a University Hospital, using the Ergonomic Methodology for the Built Environment (MEAC), proposed by Villarouco (2008), aiming at a diagnosis of the suitability of the space to its users. The results showed the real needs of adjustments to the environment meet the demands in order to achieve the objectives of Ergonomics.

\section{Introdução}

A hemodinâmica tem como principal atividade, a prestação de atendimento ao diagnóstico e terapia através da realização de exames por meio da radiologia endocardiovascular, recorrendo a cateteres e injeções de contraste, nos procedimentos como angioplastias, cateterismos, drenagens e embolizações terapêuticas. Procedimentos que são invasivos, não cirúrgicos e contribuem para um diagnóstico exato e indicação do tratamento mais adequado. A Hemodinâmica requer profissionais especializados e capacitados, onde o espaço físico é dotado de equipamentos, materiais e instalações de alta complexidade e tecnologia avançada.

Sob a ênfase da ergonomia do ambiente construído, os olhares se voltam para o ambiente físico e seu espectro analisa os diversos fatores que envolvem esse ambiente e sua influência no desempenho das atividades exercidas pelos seus usuários. Esta análise ultrapassa os limites da observação pura sobre a edificação em si, mas envolve fatores como dimensionamento, organização, layout, acessibilidade, iluminação, conforto térmico, cores, sensações percebidas, e outros condicionantes físicos que tenham influência sobre o trabalhador

(VILLAROUCO, 2011).

O presente estudo foi realizado com o objetivo de avaliar o ambiente do serviço de Hemodinâmica de um Hospital Universitário na cidade do Recife Pernambuco do ponto de vista ergonômico, a partir da Metodologia Ergonômica para o Ambiente Construído (MEAC), proposta por Villarouco (2008), que desenvolve uma abordagem ergonômica a fim de entender, avaliar, e modificar o ambiente e a interação continua com seu usuário.

\section{Metodologia}

Trata-se de uma pesquisa exploratória e qualitativa, de cunho descritivo. A população usuária do local que participou da avaliação do ambiente foi constituída por 11 profissionais de enfermagem, de um universo de 25 que trabalha na hemodinâmica. A pesquisa foi realizada de julho a agosto de 2016.

A MEAC é desenvolvida por etapas agrupadas em cinco etapas gerais, sendo as três primeiras de avaliações físicas do ambiente, a quarta de entendimento da percepção do usuário sobre o espaço usado, está no bloco perceptivo, para finalmente, na etapa cinco, ter-se o diagnóstico e as recomendações:

Etapa 1 - Análise Global do Ambiente: nesta primeira etapa foi realizada pesquisa no local escolhido, inicialmente com observação assistemática, walkthrough, registro fotográfico e entrevista com os usuários;

Etapa 2 - Identificação da Configuração Ambiental: onde foram levantados e registrados dados referentes ao ambiente físico, postos de trabalho, condições de temperatura, ventilação, iluminação, aspectos

\section{Realização: ") DE SANTA CATARINA INSTITUTO FEDERAL Santa Catarina Câmpus Palhoça Bilíngue}


construtivos, de acessibilidade e de segurança. As medições foram feitas durante o turno de trabalho;

Etapa 3 - Avaliação do Ambiente em Uso: a partir da observação, os dados coletados foram representados em mapofluxogramas;

Etapa 4 - Percepção Ambiental do Usuário: esta etapa contemplou a análise das entrevistas e demonstrou as expectativas e impressões dos usuários do ambiente. A representação gráfica foi através da ferramenta Constelação de Atributos, idealizada por Moles (1968);

Etapa 5 - Por fim, com base na análise dos dados, foram tecidos o diagnóstico e indicada as recomendações e proposição de mudanças para atender às principais necessidades e insatisfações dos usuários.

\section{Análise Ergonômica}

\subsection{Etapa 1: Análise Global do Ambiente}

O Hospital Universitário foi fundado em 1979, está localizado na cidade do Recife - PE. O setor de Hemodinâmica fica no $2^{\circ}$ andar do prédio do ambulatório, numa área construída de $296 \mathrm{~m}^{2}$ dividido em 26 ambientes e 10 postos de trabalho, é um setor fechado de acesso restrito, e proporciona à equipe multiprofissional a realização de exames de imagens através de radiação ionizante.

A Hemodinâmica funciona de segunda a sexta-feira das 7:00 as 19:00 h, com 38 profissionais (médicos, anestesistas, enfermeiros, técnicos e auxiliares de enfermagem, maqueiros, técnicos de radiologia, técnicos administrativos e auxiliares de serviços gerais). O ambiente é limpo, todavia apresenta má conservação, a iluminação é precária, o mobiliário e os equipamentos são antigos, a acústica é boa e a temperatura varia de acordo com cada ambiente.

Na sala de recuperação a equipe de enfermagem faz uma entrevista prévia com o paciente e/ou acompanhante, verifica os sinais vitais, punciona acesso venoso periférico, verifica glicemia capilar periférica, realiza tricotomia do local, e checa os exames laboratorial e de imagens. Quando o paciente retorna do exame, são aferidos os sinais vitais, faz-se o curativo, orienta o paciente quanto ao repouso, e ele só é liberado após avaliação do anestesista. O local é bem iluminado, limpo e climatizado, possui seis camas automáticas, suportes para soro, lixeiras, cadeiras plásticas para os acompanhantes, dois monitores cardíacos (antigos), carro de urgência, bomba de infusão de soro, aparelho de eletrocardiograma e de coagulação, uma escada tipo hospitalar, prateleiras com materiais descartáveis e rede de gases, porém não existe pia para a higienização das mãos, apenas um dispensador de álcool gel e não existe local para a equipe de enfermagem ficar acomodada.

Segue normas específicas como a Portaria $\mathrm{n}^{\circ} 453$ de 02/06/98 do Ministério da Saúde que estabelece requisitos de proteção radiológica e controle de qualidade para radiologia médica, odontológica e intervencionista; a NR 32, que estabelece as diretrizes para proteção à saúde dos trabalhadores nos serviços de saúde; e a RDC 50 de 2002 da Agência Nacional de Vigilância Sanitária (ANVISA), que dispõe sobre o regulamento técnico para planejamento, programação, elaboração e avaliação de projetos físicos de estabelecimentos assistenciais de saúde.

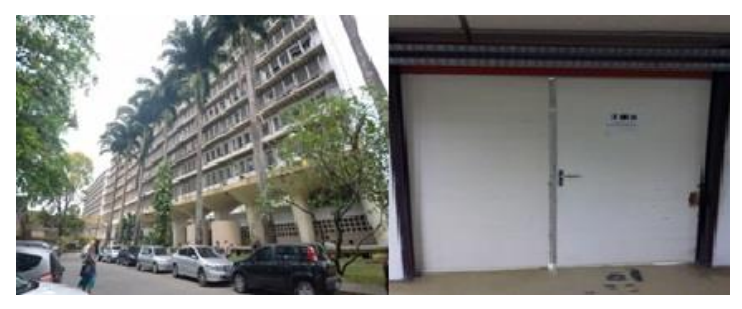

A figura 1 mostra uma vista externa do Hospital e a porta de acesso ao setor de Hemodinâmica.

Fonte: arquivo dos pesquisadores

A edificação é de $296 \mathrm{~m}^{2}$ de área construída, piso em placas vinílicas claras, paredes revestidas com chumbo (nas salas de exames), pintura acrílica semi- 
$16^{\circ}$ USIHC - Congresso Internacional de Ergonomia e Usabilidade de CINAHPA Interfaces Humano Computador

CINAHPA | 2017 - Congresso Internacional de Ambientes Hipermídia para Aprendizagem.

brilho de cor clara e teto com forro removível branco. Possui 26 (vinte e seis) ambientes: entrada, recepção, posto de enfermagem/farmácia, primeiro corredor, sala de recuperação, sala de exames (desativada), consultório médico, sala administrativa, lavabo (desativado), sala de guarda roupas, sala de chefia de enfermagem, vestiário e WC dos pacientes, sala de exames, segundo corredor, sala de comando/lavabo, sala de força, sala de gravação de exames, sala de estar médico, sala de vestiário e WC para os médicos, copa/vestiário de enfermagem, WC de enfermagem, sala de suporte para aventais de chumbo e expurgo geral.

Após realização das visitas numa perspectiva de uma abordagem macro no setor de Hemodinâmica, observamos que o ambiente é limpo, todavia apresenta uma má conservação, a iluminação é precária, o mobiliário e os equipamentos são antigos, a acústica é boa e a temperatura ambiental varia de acordo com cada ambiente.

\section{Etapa 2: Identificação da Configuração Ambiental}

Nesta etapa são identificadas as condições físicoambientais do Ambiente e todos os dados são coletados. Adquirimos a planta baixa do setor (desatualizada), vários ambientes foram modificados.

A análise realizada contemplou três ambientes: posto de enfermagem, sala de recuperação e sala de exames. No posto de enfermagem existe um balcão de fórmica (antigo) com gavetas, duas cadeiras giratórias, dois armários e uma pequena sala onde se guarda as medicações e os materiais descartáveis. É neste local onde se faz a admissão dos pacientes pela equipe de enfermagem, orientando-os a trocar de roupa, pesar e medir.

$\mathrm{Na}$ sala de exames todas as paredes tem proteção de chumbo, é bem iluminada, limpa e climatizada, tem um angiógrafo (antigo), armários e balcões em formica (antigos), negatoscópio, foco de luz (de teto), suportes de soro, carro de anestesia, monitor cardíaco, bomba de infusão de soro e bomba injetora de contraste, duas cadeiras, escada tipo hospitalar, rede de gases, duas mesas de fórmicas grandes (antigas). A sinalização indicando "equipamento em funcionamento" na entrada da sala não funciona e não tem sonorizador.

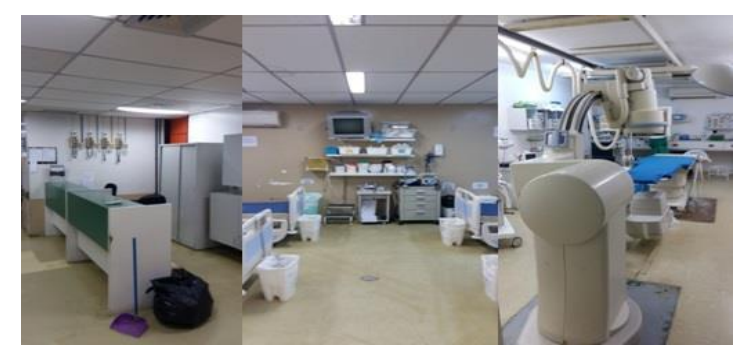

Figura 2. Posto de enfermagem, sala de recuperação e sala de exames

Fonte: Arquivo dos pesquisadores

PLANTA BAIXA DA HEMODINÂMICA

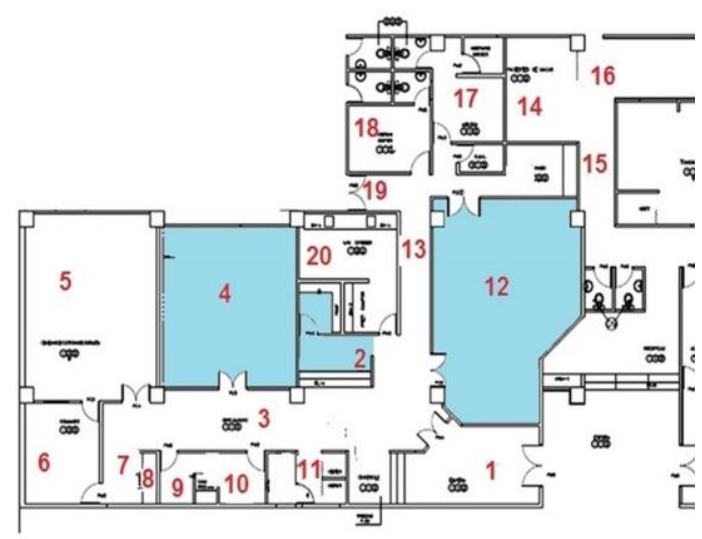

Figura 3. Planta baixa da hemodinâmica

1. Entrada/Recepção

2. Posto de enf./farmácia

3. Primeiro corredor

4. Sala de recuperação

5. Sala de exame desativada

6. Consultório médico

7. Sala do administrativo

8. Lavabo desativado

9. Sala de guardar roupas

10. Sala/chefia enfermagem

11. Vestiário e $\mathrm{WC} \mathrm{p} /$ pacientes 
$16^{\circ}$ Ergodesign - Congresso Internacional de Ergonomia e Usabilidade de Interfaces Humano Tecnológica: Produto, Informações Ambientes Construídos e Transporte

$16^{\circ}$ USIHC - Congresso Internacional de Ergonomia e Usabilidade de Interfaces Humano Computador

CINAHPA | 2017 - Congresso Internacional de Ambientes Hipermídia para Aprendizagem.

12. Sala de Exames

13. Segundo corredor

14. Sala de comando/lavabo

15. Sala de força

16. Sala de gravação

17. Estar/vestiário/WC médicos

18. Copa/vestiário/WC de enfermagem

19. Sala de suporte para aventais

20. Expurgo

\section{Acessibilidade e Desenho Universal}

A Norma Técnica utilizada para o parâmetro de avaliação dos aspectos de acessibilidade foi NBR 9050/2015 e também vimos alguns aspectos no que diz respeito à segurança, observando que o serviço não tem rota de fuga e que os extintores de incêndio estão sem sinalização e com acessos obstruídos.

O acesso ao setor de Hemodinâmica pode ser por escadas, rampas (observamos uma rampa sem corrimão) e elevadores com sinalização visual e sonora. A acessibilidade é comprometida apenas ao vestiário e WC para os pacientes devido a porta que mede $78,5 \mathrm{~cm}$ de largura, não atendendo a

especificação exigida pela legislação NBR 9050/2015 que é de $80 \mathrm{~cm}$ de largura e também não existe barras de apoio nem na vestiária e nem no WC dos mesmos.

\section{Avaliação do Conforto Lumínico}

A iluminação artificial é formada por luminárias para lâmpadas fluorescentes de $40 \mathrm{~W}$ e permanecem acesas durante toda a manhã e tarde, a noite é desligada pelo último funcionário que sai. O nível de iluminância foi medido com o aplicativo Lux Meter, para celular, os dados estão descritos no quadro a seguir e os resultados foram comparados com os níveis indicados pela norma NBR 5413/1992. Esta norma embora tenha sido revogada em 2013, para efeitos de avaliação ergonômica continua vigente, amparada pela Nota Técnica 224 de 2014 do Ministério do Trabalho e Emprego.

\section{AMBIENTE} PONTO PONTO (lux)

\begin{tabular}{|l|l|l|l|}
\hline & & 08:00h & (lux) \\
\hline Posto de Enfermagem & 3 & 140,00 & 150 \\
\hline Sala de Recuperação & 5 & 110,00 & 150 \\
\hline Sala de Exames & 15 & 250,00 & 300 \\
\hline
\end{tabular}

Tabela 1. Quadro com dados da medição do conforto lumínico

Observamos que nos três ambientes escolhidos para o estudo, a iluminação estava não conforme com a norma, provavelmente, devido a várias lâmpadas que se apresentavam queimadas.

\section{Avaliação do Conforto Acústico}

As condições de conforto acústico foram analisadas a partir das medições do ruído interno, a fim de averiguar se os resultados estariam compatíveis com os índices considerados aceitáveis pela NBR 10152 (ABNT 2000). Os pontos analisados foram os mesmos para o conforto lumínico. O nível de ruído foi medido com o aplicativo Sound Meter para celular, os dados estão descritos no quadro a segui.

\begin{tabular}{|l|l|l|l|}
\hline & MED & $\begin{array}{l}\text { NBR } \\
\text { (dB) } \\
\text { AMB:00h }\end{array}$ & $\begin{array}{l}\mathbf{1 0 1 5 2} \\
(\mathbf{d B})\end{array}$ \\
\hline Posto de Enfermagem & 3 & $83 \mathrm{~dB}$ & 35 a 45 \\
\hline Sala de Recuperação & 5 & $95 \mathrm{~dB}$ & 35 a 45 \\
\hline Sala de Exames & 15 & $88 \mathrm{~dB}$ & 35 a 45 \\
\hline
\end{tabular}

Tabela 2. Quadro com dados da medição do conforto acústico

Observamos que nos três ambientes escolhidos para o estudo, a acústica estava também não conforme com a norma, provavelmente, devido ao grande fluxo de pessoas circulando no ambiente e equipamentos em funcionamento.

\section{Avaliação do Conforto Térmico}

A NR 17 Sugere variação de $20^{\circ} \mathrm{C}$ a $23^{\circ} \mathrm{C}$. Na sala do administrativo possui um condicionador de ar split de marca yang de 1.800 btu's, na sala de recuperação um split maxiflex de 30.000 btu's, na sala de exames, dois splits um rheem de 8.000 btu's e um springer 
maxiflex de 30.000 btu's, na sala de força tem dois splint, um Elgin de 3.000 btu's e outro de 1.800 btu's e na sala de gravação um Split yang de 1.800 btu's. O nível de temperatura foi medido com um aparelho TERMO ANEMÔMETRO DIGITAL MDA-II, os dados estão descritos no quadro a seguir.

\begin{tabular}{|l|l|l|l|}
\hline & PONTO & $\begin{array}{l}\text { MED } \\
\left({ }^{\circ} \mathbf{C}\right) \\
\mathbf{0 8 : 0 0 h}\end{array}$ & $\begin{array}{l}\text { NR 17 } \\
\left(\mathbf{2 0 - 2 3}{ }^{\circ} \mathbf{C}\right)\end{array}$ \\
\hline Posto de Enfermagem & 3 & $26.0^{\circ} \mathrm{C}$ & $20-23^{\circ} \mathrm{C}$ \\
\hline Sala de Recuperação & 5 & $23,6^{\circ} \mathrm{C}$ & $20-23^{\circ} \mathrm{C}$ \\
\hline Sala de Exames & 15 & $19,5^{\circ} \mathrm{C}$ & $20-23^{\circ} \mathrm{C}$ \\
\hline
\end{tabular}

Tabela 3. Quadro com dados da medição do conforto térmico

Observamos no que diz respeito à temperatura, que os três ambientes estão não conformes em relação com a norma, e que na sala de exames os equipamentos precisam trabalhar em ambiente extremamente frio, evitando danos aos mesmos.

\subsubsection{Avaliação do Ambiente em Uso}

\section{Avaliação do Ambiente em uso no Desempenho de suas Atividades:}

Nesta etapa podemos avaliar a eficiência da edificação e seus espaços para o desenvolvimento dos procedimentos realizados na Hemodinâmica.

\section{Fluxograma}

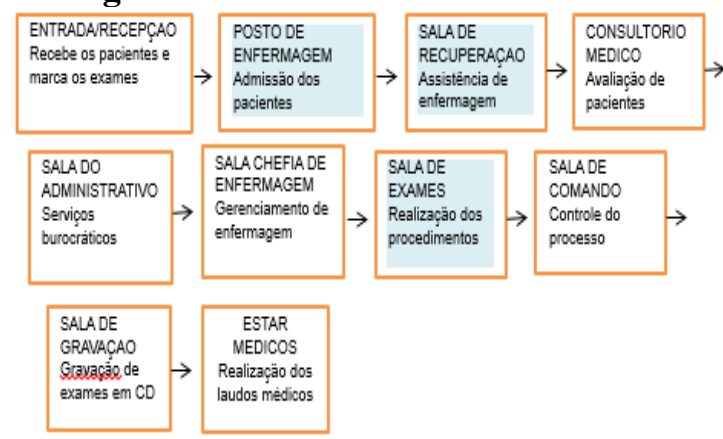

Figura 4. Fluxograma dos postos de trabalho e suas atividades
$\mathrm{Na}$ figura acima, esquematizamos os diferentes postos de trabalho que compõem o setor de Hemodinâmica, descrevendo as funções exercidas para o cumprimento dos procedimentos realizados.

POSTO DE ENFERMAGEM: Local onde recebemos os pacientes e acompanhantes com as fichas para breve entrevista e troca de roupas, disponibilizado um balcão grande em fórmica com gavetas, três cadeiras pretas giratórias e reguláveis, material de escritório, um telefone de ramal e dois armários grandes (antigos) de fórmica.

SALA DE RECUPERAÇÃO: Local onde se faz o pré e pós exames, no pré: os pacientes ficam deitados de roupa trocada, já foram pesados e medidos, a enfermagem verifica os sinais vitais, punciona um acesso venoso periférico, realiza tricotomia e faz a glicemia capilar periférica, os mesmo permanecem em dieta zero antes do exame e seus acompanhantes sentados em cadeiras ao lado da cama. No pós: os pacientes retornam para o mesmo leito, a enfermeira realiza o curativo, libera dieta e ficam em repouso de acordo com o procedimento realizado e só são liberados após avaliação do anestesista. A mobília é composta de seis camas automáticas, seis cadeiras plásticas para acompanhantes, seis suportes de soro, duas escadas tipo hospitalar (antigas) pintadas, dois biombos, três prateleiras com os monitores cardíacos (antigos), uma rede de gases em cada leito com ar comprimido, oxigênio e vácuo, um aparelho de eletrocardiógrafo, um carrinho de emergência com desfibrilador, medicações e materiais descartáveis, um compressor mecânico, uma TV (antiga), duas prateleiras com soros e materiais descartáveis, um condicionador de ar e dez lixeiras sem tampa para (lixo contaminado, lixo comum, frascos de soros vazios e restos alimentares) e uma caixa para descarte de materiais pérfuro-cortantes. E quando superlotado, duas macas ficam no corredor dentro da sala de recuperação dificultando a acessibilidade.

Observamos a falta de uma pia para higienização das mãos, em desacordo com a RDC 50.

SALA DE EXAMES: Local para realização dos exames. Todas as paredes com proteção de chumbo
Realização:

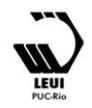


$16^{\circ}$ USIHC - Congresso Internacional de Ergonomia e Usabilidade de Interfaces Humano Computador

CINAHPA | 2017 - Congresso Internacional de Ambientes Hipermídia para Aprendizagem.

como preconiza a legislação, a iluminação aparentemente boa, mesmo faltando algumas lâmpadas, ambiente limpo e climatizado por dois condicionadores de ar, o piso precisando ser trocado, com um angiógrafo (antigo), armários e balcões em fórmica (antigos), negatoscópio, foco de teto, suporte de soros, carro de anestesia, monitor cardíaco, bomba de infusão de soro, uma bomba injetora de contraste, duas cadeiras, escada tipo hospitalar, rede de gases, duas mesas de formicas grandes (antigas), dois quadros brancos. A sinalização indicando equipamento em funcionamento na entrada da sala não funciona e não tem sonorizador dentro da sala para comunicação com a sala de comando na parte externa.

\section{Avaliação antropométrica}

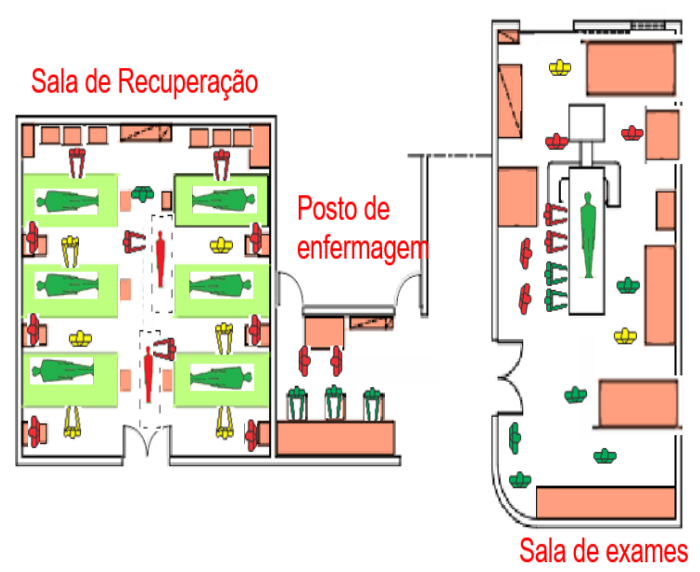

Figura 5. Avaliação Antropométrica

O layout da sala de recuperação nos permite identificar que a circulação de pessoas torna-se dificultada pelo elevado número de usuários. A sala, nos mostra que pela sua finalidade, deveria estar melhor disposta quanto ao mobiliário, bem como maior restrição de usuários circulantes. Os pontos críticos observados são o corredor e a lateral dos leitos dos pacientes. Um dos problemas de maior importância ergonômica deve-se à falta de espaço para colocação de macas, tendo em vista que muitos procedimentos acontecem num curto período de tempo, causando desconforto aos próximos pacientes que estão à espera do seu procedimento. Outro ponto de não conformidade foi o posto de enfermagem, $o$ qual além de mal estruturado, possui pouco espaço e falta de cadeiras para os profissionais e a existência de armários na parede, dificultando a circulação dos usuários no posto de enfermagem. No tocante à sala de exames, observa-se amplitude do espaço, bem como variação de possibilidades de acomodação do mobiliário. Os espaços entre os profissionais podem ser melhorados, diminuindo o número dos mesmos no momento de cada procedimento.

\subsection{Etapa 4: Percepção Ambiental do Usuário}

De acordo com Villarouco (2008), um ponto importante da avaliação do ambiente construído é a percepção do usuário, por ser o elemento que mais sofre com todas as sensações que o ambiente pode gerar.

Assim, foi aplicada a Constelação de Atributos, ferramenta idealizada por Moles em 1968 e que permite a compreensão da consciência psicológica do usuário frente ao espaço que ocupa. Esta representação gráfica é composta por um núcleo que representa o objeto de estudo e por "estrelas" que representam os atributos especiais. A distância entre o atributo e o núcleo, chamada de distância psicológica, determina o grau de importância de cada atributo, além de auxiliar no conhecimento da percepção do usuário em relação ao ambiente (VASCONCELOS; VILLAROUCO; SOARES, 2009).

Para a construção do gráfico da Constelação de Atributos foram realizadas duas perguntas, propiciando a análise de duas esferas do ambiente construído: uma para a conceituação do Serviço de Hemodinâmica Imaginário (Ideal), com associação de ideias voltadas para as características espontâneas, e outra que define o serviço de Hemodinâmica Real, com associação de ideias a partir de características induzidas.

Segundo Vasconcelos; Villarouco; Soares (2010), ao analisarmos o grau de aproximação e/ou afastamento 
das variáveis nas constelações dos atributos, percebese que aqueles elementos mais próximos do centro, onde está representado o objeto de estudo, exercem uma relação mais direta para explicar o fenômeno de percepção e adaptação do espaço. Os que estão mais afastados demonstram o fenômeno observado com menor propriedade.

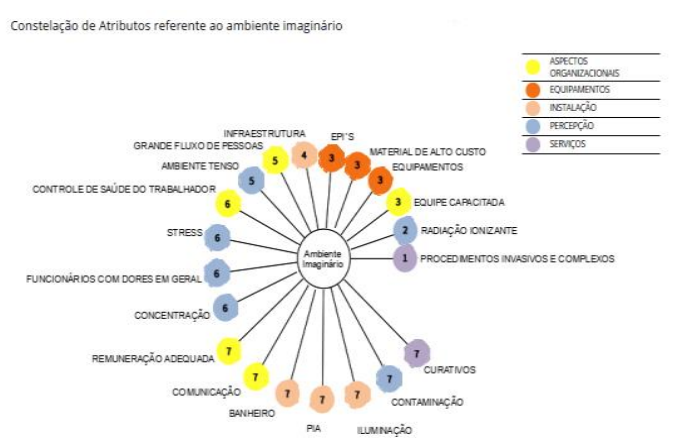

Figura 6. Constelação de atributos Hemodinâmica IDEAL

A constelação de atributos IDEAL é baseada na pergunta que pede respostas relacionadas à expectativa de uso de um ambiente imaginário, identificando aspectos que o usuário deseja, ou seja, um ambiente considerado ideal e que o satisfaça em diversos sentidos. Já a constelação de atributos REAL é baseada na pergunta que requer respostas de cunho objetivo, onde o entrevistado irá falar sobre o ambiente que está frequentando, opinando através de uma visão real.

Importante salientar na avaliação da constelação de atributos para a Hemodinâmica Ideal que os profissionais de enfermagem demonstraram a percepção de um ambiente bem estruturado e organizado, que reflete em um melhor atendimento ao usuário no que diz respeito à realização dos procedimentos invasivos e complexos, assim como, a questão da segurança na proteção contra a radiação ionizante. Estes fatores de maior expressão apontam para uma grande importância dada aos atributos relativos aos aspectos organizacionais, os quais estão diretamente ligados à qualidade do trabalho prestado e satisfação dos profissionais.

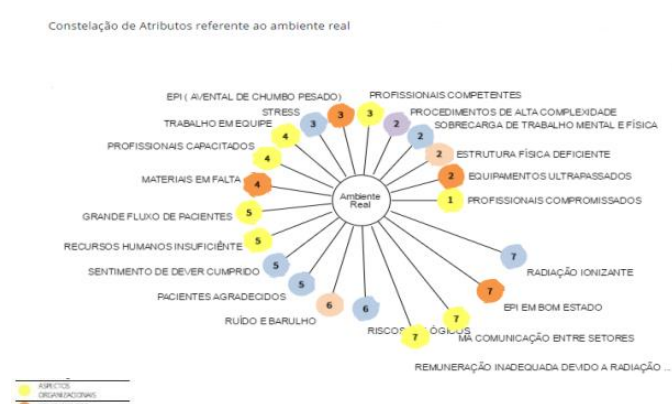

Figura 7. Constelação de atributos Hemodinâmica REAL

Na avaliação do mapa da constelação de atributos para o ambiente Real, observa-se que os profissionais de enfermagem da hemodinâmica são compromissados, percebem uma sobrecarga de trabalho mental e física, realizam procedimentos de alta complexidade, mesmo com uma estrutura física deficiente, o que deveria contribuir negativamente para a realização de suas atividades. Esses fatores são de relevante importância não apenas para avaliação da satisfação dos usuários, bem como das instalações físicas. Em relação aos fatores organizacionais, estes aparecem em grande número de citações, principalmente quanto à comunicação entre setores. Fatores como estes deverão ser repassados à direção desta unidade no sentido de otimizar o trabalho realizado e melhorar a satisfação dos usuários que fazem parte desta unidade.

Apesar de se ter por finalidade na Constelação de Atributos, obter a percepção dos usuários quanto ao ambiente, ao espaço físico, o que se percebe é que, quando o trabalho e seus condicionantes exercem uma grande influência e preocupação aos trabalhadores, estes não conseguem se ater ao objeto questionado na aplicação da ferramenta. Isto está aqui demonstrado, quando grandes partes das respostas não se referem ao ambiente físico investigado.

\subsection{Etapa 5: Diagnóstico Ergonômico do Ambiente} e Recomendações
Realização:

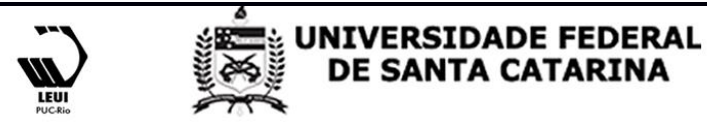

INSTITUTO FEDERAL

Santa Catarina Câmpus Palhoça Bilíngue 


\section{ERGODESIGN USIHC CINAHPA}

$16^{\circ}$ Ergodesign - Congresso Internacional de Ergonomia e Usabilidade de Interfaces Humano Tecnológica: Produto, Informações Ambientes Construídos e Transporte

$16^{\circ}$ USIHC - Congresso Internacional de Ergonomia e Usabilidade de Interfaces Humano Computador

CINAHPA | 2017 - Congresso Internacional de Ambientes Hipermídia para Aprendizagem.

De um modo geral, com intuito de eliminar ou diminuir os problemas identificados, e portanto melhorar o desenvolvimento das atividades no trabalho e a satisfação dos usuários, construiu-se o quadro abaixo com os respectivos diagnósticos e as recomendações que deverão ser realizadas a curto, médio e longo prazo, a partir dos problemas identificados pela percepção dos pesquisadores e usuários, além dos dados levantados pelas entrevistas, medições, observações e questionários.

\begin{tabular}{|c|c|}
\hline DIAGNÓSTICOS & RECOMENDAÇÕES \\
\hline $\begin{array}{l}\text { Sala de Exames sem áudio } \\
\text { e com a Lâmpada de } \\
\text { sinalização visual } \\
\text { "queimada". }\end{array}$ & $\begin{array}{l}\text { Instalar sonorizador dentro } \\
\text { da sala de exames e trocar a } \\
\text { lâmpada de sinalização } \\
\text { visual. }\end{array}$ \\
\hline $\begin{array}{l}\text { Extintores sem sinalização } \\
\text { e com acesso obstruído. }\end{array}$ & $\begin{array}{l}\text { Sinalizar adequadamente os } \\
\text { extintores e liberar o acesso } \\
\text { aos mesmos. }\end{array}$ \\
\hline $\begin{array}{l}\text { Copa e vestiário juntos, e } \\
\text { WC único para ambos os } \\
\text { gêneros de profissionais. }\end{array}$ & $\begin{array}{l}\text { Separar a copa do vestiário e } \\
\text { do WC dos funcionários, e } \\
\text { providenciar WC separados. }\end{array}$ \\
\hline $\begin{array}{l}\text { Sala de recuperação sem } \\
\text { pia para higienização das } \\
\text { mãos. }\end{array}$ & $\begin{array}{l}\text { Instalação de uma pia para } \\
\text { higienização das mãos na } \\
\text { sala de recuperação. }\end{array}$ \\
\hline $\begin{array}{l}\text { WC dos pacientes sem } \\
\text { barra de segurança. }\end{array}$ & $\begin{array}{l}\text { Instalação de barra de } \\
\text { segurança no WC dos } \\
\text { pacientes. }\end{array}$ \\
\hline $\begin{array}{l}\text { Vestiário dos pacientes } \\
\text { com porta medindo } 78,5 \\
\mathrm{~cm} .\end{array}$ & $\begin{array}{l}\text { Ampliar a porta do vestiário } \\
\text { dos pacientes. }\end{array}$ \\
\hline $\begin{array}{l}\text { Grande fluxo de pessoas na } \\
\text { sala de recuperação. }\end{array}$ & $\begin{array}{l}\text { Minimizar a entrada de } \\
\text { acompanhantes na sala de } \\
\text { recuperação. }\end{array}$ \\
\hline $\begin{array}{l}\text { Leitos da sala de } \\
\text { recuperação sem } \\
\text { divisórias. }\end{array}$ & $\begin{array}{l}\text { Instalar divisórias nos leitos } \\
\text { da sala de recuperação. }\end{array}$ \\
\hline $\begin{array}{l}\text { Mobiliários e } \\
\text { equipamentos antigos e } \\
\text { ultrapassados. }\end{array}$ & $\begin{array}{l}\text { Aquisição de mobiliários e } \\
\text { equipamentos novos e } \\
\text { adequados. }\end{array}$ \\
\hline $\begin{array}{l}\text { Armários de parede } \\
\text { prejudicando o fluxo dos } \\
\text { profissionais no posto de } \\
\text { enfermagem. }\end{array}$ & $\begin{array}{l}\text { Retirar os armários de parede } \\
\text { do posto de enfermagem. }\end{array}$ \\
\hline RH insuficiente. & Redimensionamento de RH. \\
\hline $\begin{array}{l}\text { Falha na comunicação } \\
\text { entre setores. }\end{array}$ & $\begin{array}{l}\text { Criar protocolos de } \\
\text { comunicação entre setores. }\end{array}$ \\
\hline $\begin{array}{l}\text { Aventais de chumbo muito } \\
\text { pesado }(6 \mathrm{~kg}) .\end{array}$ & $\begin{array}{l}\text { Aquisição de aventais de } \\
\text { chumbo mais leves. }\end{array}$ \\
\hline
\end{tabular}

Tabela 4. Quadro com diagnósticos e recomendações
Foi percebido, através da análise do ambiente, que a Hemodinâmica atende às necessidades a que se propõe. Por sua dimensão teria um potencial para uma maior produtividade se fossem feitos os ajustes necessários. A sala de procedimentos foi considerada bem estruturada fisicamente e respeita quase sempre ao preconizado para as variáveis ambientais e de conforto, necessitando apenas de modernização e revisão de mobiliários existentes bem como a aquisição de equipamentos novos. Em relação ao conforto do ambiente, percebe-se que, pelo alto número de usuários, elevam-se os ruídos e a temperatura. $\mathrm{O}$ layout apresenta alguns pontos críticos, por se tratar de um hospital escola, a circulação de pessoas é maior que o normal, necessitando de mais espaços ou redução do número de pessoas que transitam durante os procedimentos. Os usuários relatam alguns problemas relacionados à iluminação. Para esta variável é importante destacar que a iluminação da sala de procedimentos obedece aos parâmetros. A alta temperatura foi destacada por alguns dos entrevistados, que se dá também pelo número elevado de pessoas circulando. Os três postos de trabalho avaliados foram identificados pela equipe como razoáveis. Os materiais utilizados nos acabamentos destas três unidades atendem às normas específicas, permitindo boa limpeza e evitando maiores riscos de infecção. Em relação a sala de recuperação, necessita de melhor adequação, tais como minimizar a presença de acompanhantes e colocação de pia para higienização das mãos. O posto de enfermagem apresenta dificuldade de circulação devido aos armários afixados na parede, que poderiam ser retirados, facilitando a circulação dos usuários. A sala de procedimentos, por ter um aumento do número de profissionais de acordo com o tipo de exame e também de acordo com as variáveis antropométricas do profissionais, não apresenta muitas possibilidades de mudanças.

\section{Conclusão}

Como parte da atividade da Disciplina de Ergonomia do Ambiente Construído, dentro do programa de Mestrado Profissional de Ergonomia da UFPE, essa atividade veio com o incentivo de inserir os

\section{Realização:

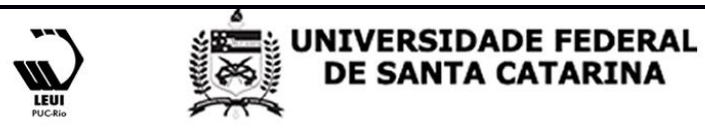




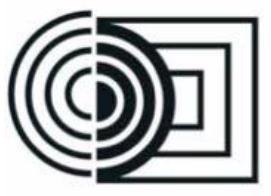

$16^{\circ}$ Ergodesign - Congresso Internacional de Ergonomia e Usabilidade de Interfaces Humano Tecnológica: Produto, Informações Ambientes Construídos e Transporte

$16^{\circ}$ USIHC - Congresso Internacional de Ergonomia e Usabilidade de Interfaces Humano Computador

CINAHPA | 2017 - Congresso Internacional de Ambientes Hipermídia para Aprendizagem. mestrandos em um cenário de avaliação prática no campo da metodologia de análise ergonômica.

Esta pesquisa possibilitou avaliar o ambiente do serviço de Hemodinâmica através da MEAC, e após o estudo verificou-se a necessidade de algumas intervenções, foi proposto recomendações que deverão ser realizadas a curto, médio e em longo prazo.

Os resultados comprovam que a Ergonomia pode contribuir de forma positiva para a melhoria da qualidade de vida dos profissionais de enfermagem e da assistência prestada aos pacientes usuários do ambiente em estudo.

\section{Referências}

ASSOCIAÇÃO BRASILEIRA DE NORMAS TÉCNICAS. NBR 10152: níveis de ruído para conforto acústico. Rio de Janeiro, 2000.

ASSOCIAÇÃO BRASILEIRA DE NORMAS TÉCNICAS. NBR 9050 - Acessibilidade a edificações, mobiliário espaços e equipamento urbanos. Rio de Janeiro, 2015.

ASSOCIAÇÃO BRASILEIRA DE NORMAS TÉCNICAS. NBR 5413: iluminância de interiores. Rio de Janeiro, 1992. 13 p.BRASIL. Ministério do Trabalho e Emprego. NR 17 - Ergonomia. Brasília: 2007.

GUIMARÃES, Lia Buarque de Macedo. Introdução à ergonomia. In: Guimarães, Lia Buarque de Macedo. Ergonomia de Processo, volume 1. Porto Alegre, FEENG/UFRGS. 2004.

MOLES, A. Sociodinâmica de La cultura. Barcelona: Editora Gustavo Gili, 1968.

MONT`ALVÃO, C.; VILLAROUCO, V. Um Novo Olhar para o Projeto: a ergonomia no ambiente construído - Teresópolis: 2AB, 2011.
VASCONCELOS, C.F.; VILLAROUCO, V.; SOARES, M. M. Avaliação ergonômica do ambiente construído: estudo de caso de uma biblioteca universitária. Ação ergonômica, v.4.p. 5$25,2009$.

VILLAROUCO, V.; ANDRETO, L. F. M. Avaliando desempenho de espaços de trabalho sob o enfoque da ergonomia do ambiente construído. Produção, v. 18, n. 3, p. 523-539, 2008.

VILLAROUCO, V. FALCÃO E VASCONCELOS; SOARES M.M. Contribuição da psicologia ambiental na análise ergonômica do ambiente construído. Ação Ergonômica. V. 5, n. 3, dez/2010. 